\title{
Asian American Access to Care in the Affordable Care Act Era: Findings from a Population-Based Survey in California
}

Kevin H. Nguyen, $\mathrm{MS}^{l}$ and Amal N. Trivedi, MD, MPH ${ }^{1,2}$

'Brown University School of Public Health, Providence, RI, USA; ${ }^{2}$ Providence Veterans Affairs Medical Center, Providence, RI, USA.

BACKGROUND: Though Asian Americans made gains in coverage following the Affordable Care Act (ACA), substantial variations in access to care remain across different ethnic subgroups. Several states are considering adoption of policies to collect health data for Asian Americans that is disaggregated by ethnic subgroup, which may identify disparities in access to care.

OBJECTIVE: We examined coverage and access to care between non-Hispanic White and Asian American adults following the ACA in California. We first compared outcomes in non-Hispanic White adults with all Asian Americans in our sample, and then evaluated whether we detect disparities when data is disaggregated into five of the most populous ethnic subgroups (Chinese, Korean, Filipino, Vietnamese, and Japanese).

DESIGN: Cross-sectional California Health Interview Survey data were collected between January 2014 and December 2016.

PARTICIPANTS: Our sample included 19,201 nonHispanic White and 3077 Asian American non-elderly adults age 18 to 64 living in California.

MAIN MEASURES: Our outcomes were (1) being uninsured, (2) having a usual source of care, (3) delaying necessary medical care, and (4) delaying necessary prescription medications. Using multivariable logistic regression models, we examined our outcomes, adjusting for predisposing, enabling, need, and acculturation factors.

KEY RESULTS: Compared with non-Hispanic Whites, some subgroups of Asian Americans reported significantly worse access to care: disaggregated, adjusted analyses revealed that Koreans were significantly less likely to report a usual source of care (adjusted odds ratio $[A O R]=0.31$, $p<0.01)$ relative to non-Hispanic Whites. Chinese $(\mathrm{AOR}=$ $0.42, p<0.01)$ and Vietnamese $(\mathrm{AOR}=0.34, p<0.01)$ adults were significantly less likely to delay necessary care. CONCLUSIONS: Disaggregated analyses identified differences in access to care for Asian American subgroups following the ACA. State policies to collect disaggregated health data for Asian Americans may reveal heterogeneity in experiences of care and inform specific policies to reduce disparities in access to care.

KEY WORDS: access to care; disparities; minority health; health care reform; health policy.

Prior Presentations This article was presented in Washington, D.C. at the Annual AHRQ NRSA Trainees Research Conference on June 1, 2019 and the Academu Health Annual Research Meeting on June 3.2019.

Received November 5, 2018

Revised May 14, 2019

Accepted August 16, 2019

Published online September 11, 2019
J Gen Intern Med 34(11):2660-8

DOI: $10.1007 /$ s 11606-019-05328-5

(C) Society of General Internal Medicine 2019

\section{INTRODUCTION}

Approximately 17.8 million individuals in the USA, comprising $6 \%$ of the population, self-identify as Asian American. ${ }^{1}$ One of the fastest growing populations in the country, Asian Americans are a diverse race, encompassing more than 50 ethnicities and 100 languages spoken. ${ }^{2,} 3$ The sociodemographic heterogeneity of this racial group has led to efforts that standardize disaggregation of Asian American health data in state and federal surveys over the last decade; however, many of these items have not been widely adopted and variations in access to care among Asian American subgroups remain unknown. ${ }^{4,5}$ The Office of Minority Health developed standards for disaggregating Asian American data as part of the Affordable Care Act (ACA), resulting in more granular data collection for some groups (e.g., Asian Indians, Chinese, Filipinos, Japanese, Koreans, Vietnamese), but not other groups (e.g., Bangladeshi, Burmese). ${ }^{2}$

Evidence suggests that Asian Americans have worse selfreported mental health ${ }^{6}$ and higher rates of chronic conditions, ${ }^{7,} 8$ compared with non-Hispanic Whites. However, despite these documented disparities and unique challenges in navigating the health care system-including language barriers and health literacy - there is limited recent evidence regarding access to care among Asian Americans. ${ }^{9}, 10$ Many prior studies have aggregated outcomes for the entire Asian American population; aggregated analyses may fail to detect important disparities for some subgroups. ${ }^{11-14}$ Further, they have used data predating the implementation of the ACA, which attempted to reduce disparities in access to and affordability of care through expansion of Medicaid eligibility, availability of parental coverage for dependents 26 and under, and reducing cost-sharing for routine preventive visits. Asian Americans made sizable gains in coverage following the insurance expansions in 2014, but substantial variations in rates in uninsurance remained across subgroups. ${ }^{1,15-20}$

We examined differences in coverage and access to care between non-Hispanic White and Asian American non-elderly adults in California 3 years after the ACA, between 2014 and 2016. To assess what differences may or may not be captured by aggregated data, we first compared outcomes in non- 
Hispanic White adults with all Asian Americans (aggregated) and then examined outcomes for five of the most populous subgroups in California: Chinese, Korean, Filipino, Vietnamese, and Japanese.

\section{METHODS}

\section{Data}

The nation's largest state health survey, California Health Interview Survey (CHIS) is a state-representative, randomdigit-dial telephone survey administered annually to about 20,000 households by the University of California, Los Angeles Center for Health Policy Research in collaboration with the California Department of Public Health and Department of Health Care services. ${ }^{21}$ Its sampling frame uses both landline and cell phone random-digit-dialing techniques, as well as a supplemental surname list to ensure accurate representation from Korean and Vietnamese households.

CHIS is also one of the few publicly available, federally or state-administered surveys that asks about specific ethnic subgroup among Asian American respondents. To accurately reflect the diversity of the state, CHIS is conducted in multiple languages including Chinese (Cantonese and Mandarin dialects), Korean, Tagalog, and Vietnamese.

\section{Outcomes}

Our outcomes were (1) being uninsured, (2) having a usual source of care, (3) delaying necessary medical care in the past 12 months, and (4) delaying or not getting medication prescribed by a doctor in the last 12 months. As secondary outcome, we also examined whether respondents reported a clinic or health center as their usual site of care, among those who reported having a usual source of care.

\section{Study Sample}

We pooled 3 years of CHIS data collected between January 2014 and December 2016. Our sample included adults age 18-64 who self-identified as either nonHispanic White or non-Hispanic Asian American residing in California. Given our focus on insurance coverage and access to care following the ACA, we excluded adults age 65 or older, because Medicare provides nearly universal coverage for this group. Consistent with previous studies, we excluded respondents reporting other races and ethnicities (Hispanic or Latino, Black or African American, individuals reporting multiple races, and Asian respondents who reported more than one Asian ethnicity). ${ }^{15} \mathrm{We}$ also excluded respondents who self-identified as "Other Asian," a category that is comprised of Cambodian, Hmong, Indian, Indonesian, Laotian, Malaysian, Pakistani, Sri Lankan, Taiwanese, Thai, and other subgroups. While it is unclear how these groups are distributed within this category, this aggregation likely indicates a small number of respondents in each subgroup, and an opportunity for future analyses was further disaggregated data to become available. We grouped respondents into six mutually exclusive categories: White, Chinese, Korean, Filipino, Vietnamese, and Japanese.

\section{Andersen Behavioral Model for Health Services Use}

The Andersen behavioral model is a conceptual framework that conceives access to and utilization of care as a function of three main factors: an individual's beliefs or propensity (predisposing factors), resources (enabling factors), and perceived need for health services. ${ }^{22}$ Iterations of the Andersen model have integrated social or structural determinants of access that are more racially or ethnically specific, with some studies identifying acculturation factors (e.g., English proficiency, length of residence) as key drivers of differences in access to care between Asian Americans and Whites. ${ }^{18-20,23-25}$

\section{Statistical Analysis}

We used Pearson's chi-square tests to describe differences first between White and all Asian Americans in our sample (aggregated), and then compared differences across White and the five subgroups (disaggregated). We also examined the characteristics of respondents who identified as "Other Asian" or who reported more than one Asian subgroup, which we present in a supplementary analysis. We first calculated unadjusted rates of each of our outcomes. We then estimated logistic regression models across our outcomes using the Andersen behavioral model: we adjusted for predisposing factors (e.g., age, gender, highest level of education attained, marital status, and household size), enabling factors (e.g., household income measured as a percentage of the federal poverty level, employment status, urban/rural designation, and being uninsured), need factors (e.g., self-reported health status), and acculturation factors (e.g., being born in the USA, percent of life spent in the USA, citizenship status, and English proficiency). ${ }^{26-28}$ To examine the degree to which these characteristics explained differences in access to care between White and Asian American respondents, we constructed five models: model 1 was unadjusted, model 2 included predisposing characteristics, model 3 added enabling factors, model 4 added need factors, and model 5 added acculturation factors. As a sensitivity analysis, we also included respondents who identified as "Other Asian" or reported more than one subgroup in our aggregated group. Consistent with previous studies examining disaggregated Asian subgroups, we applied a more conservative alpha level $(p<0.01)$ to account for multiple comparisons. $^{29,} 30$

Our regression models used jackknife replication variance estimates and applied survey weights to account for the 
complex sampling design of CHIS. All analyses were conducted in Stata 15 (StataCorp LP, College Station, TX, USA).

\section{RESULTS}

Our unweighted sample consisted of 22,098 respondents, of which 19,021 were White and 3077 were Asian American: 1247 were Chinese, 327 were Korean, 560 were Filipino, 585 were Vietnamese, and 358 were Japanese. Our weighted sample characteristics comparing White respondents and all Asian
American respondents (aggregate) and disaggregated into five subgroups are presented in Table 1. Relative to White respondents, significantly more Asian American respondents reported having a college degree or higher $(59.00 \%$ vs. $48.90 \%$, $p<0.01$ ) however, significantly fewer Asian American respondents reported earning more than $400 \%$ of FPL (48.23\% vs. $56.05 \%, p<0.01)$.

When disaggregated into five subgroups, significantly fewer Vietnamese respondents reported having a college degree or higher $(39.00 \%, p<0.01)$ relative to White respondents $(48.90 \%)$. There was wide variation in income: more than one-

Table 1 Characteristics of Non-Hispanic White and Asian Respondents, Disaggregated by Subgroup, 2014-2016

\begin{tabular}{|c|c|c|c|c|c|c|c|c|c|c|c|c|c|}
\hline & \multirow[t]{2}{*}{$\begin{array}{l}\text { White } \\
n= \\
19,021\end{array}$} & \multicolumn{2}{|c|}{$\begin{array}{l}\text { Asian } \\
\text { Americans } \\
\text { (aggregate) } \\
n=\mathbf{3 0 7 7}\end{array}$} & \multicolumn{2}{|c|}{$\begin{array}{l}\text { Chinese } \\
n=1247\end{array}$} & \multicolumn{2}{|c|}{$\begin{array}{l}\text { Korean } \\
n=327\end{array}$} & \multicolumn{2}{|c|}{$\begin{array}{l}\text { Filipino } \\
n=560\end{array}$} & \multicolumn{2}{|c|}{$\begin{array}{l}\text { Vietnamese } \\
n=585\end{array}$} & \multicolumn{2}{|c|}{$\begin{array}{l}\text { Japanese } \\
n=358\end{array}$} \\
\hline & & $\%$ & $p^{*}$ & $\%$ & $p^{*}$ & $\%$ & $p^{*}$ & $\%$ & $p^{*}$ & $\%$ & $p^{*}$ & $\%$ & $p^{*}$ \\
\hline \multicolumn{14}{|l|}{ Predisposing factors } \\
\hline \multicolumn{14}{|l|}{ Age } \\
\hline $18-34$ & 32.44 & 40.89 & $<$ & 44.22 & $<$ & 46.19 & 0.03 & 40.82 & 0.05 & 35.13 & 0.56 & 25.53 & 0.32 \\
\hline $35-64$ & 67.66 & 59.11 & 0.01 & 55.78 & 0.01 & 53.81 & & 59.18 & & 64.87 & & 74.47 & \\
\hline Female & 49.21 & 54.22 & $\begin{array}{l}< \\
0.01\end{array}$ & 53.43 & 0.13 & 61.39 & 0.03 & 52.32 & 0.37 & 51.53 & 0.63 & 61.45 & 0.10 \\
\hline Education & & & & & & & & & & & & & \\
\hline $\begin{array}{l}\text { Does not have high school } \\
\text { diploma }\end{array}$ & 3.95 & 6.78 & $\begin{array}{l}< \\
0.01\end{array}$ & 7.22 & $\begin{array}{l}< \\
0.01\end{array}$ & 2.99 & 0.16 & 0.86 & 0.05 & 23.13 & $\begin{array}{l}< \\
0.01\end{array}$ & 0.88 & 0.01 \\
\hline High school diploma & 19.33 & 15.38 & & 12.09 & & 16.82 & & 15.20 & & 23.38 & & 10.66 & \\
\hline Some college & 15.74 & 12.11 & & 7.98 & & 11.06 & & 18.82 & & 10.27 & & 5.95 & \\
\hline Vocational school/AA or & 12.09 & 6.73 & & 4.23 & & 6.54 & & 9.49 & & 4.21 & & 13.53 & \\
\hline AS degree & & & & & & & & & & & & & \\
\hline College degree or higher & 48.90 & 59.00 & & 68.47 & & 62.60 & & 55.64 & & 39.00 & & 68.98 & \\
\hline Marital status: married & 51.68 & 53.38 & 0.42 & 51.87 & 0.96 & 54.24 & 0.67 & 50.49 & 0.78 & 59.18 & 0.11 & 61.02 & 0.14 \\
\hline \multicolumn{14}{|c|}{ Enabling factors } \\
\hline \multicolumn{14}{|c|}{ Income, by federal poverty level (FPL) } \\
\hline $0-138 \%$ FPL & 14.34 & 20.24 & $<$ & 19.30 & 0.23 & 16.61 & 0.31 & 16.94 & 0.07 & 36.93 & $<$ & 6.29 & 0.35 \\
\hline $139-249 \%$ FPL & 12.27 & 13.86 & 0.01 & 10.89 & & 17.18 & & 16.68 & & 13.25 & 0.01 & 9.97 & \\
\hline $250-399 \%$ FPL & 17.34 & 17.66 & & 16.39 & & 20.65 & & 19.84 & & 13.63 & & 17.43 & \\
\hline $400 \%$ FPL or more & 56.05 & 48.23 & & 53.41 & & 45.56 & & 46.54 & & 36.19 & & 66.32 & \\
\hline Unemployed & 25.48 & 23.85 & 0.40 & 22.87 & 0.39 & 27.13 & 0.77 & 22.20 & 0.35 & 27.89 & 0.56 & 20.53 & 0.33 \\
\hline \multicolumn{14}{|l|}{ Health insurance coverage } \\
\hline Uninsured & 7.28 & 10.26 & 0.01 & 9.03 & 0.32 & 10.48 & 0.20 & 10.62 & 0.12 & 12.86 & 0.02 & 8.45 & 0.75 \\
\hline Employer-sponsored & 62.84 & 58.63 & 0.03 & 61.33 & 0.63 & 47.63 & 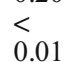 & 63.93 & 0.78 & 46.93 & 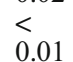 & 69.30 & 0.27 \\
\hline Medicaid & 14.61 & 18.79 & 0.01 & 14.34 & 0.91 & 19.09 & 0.31 & 19.84 & 0.08 & 29.47 & $<$ & 9.04 & 0.30 \\
\hline Individually purchased & 10.92 & 10.55 & 0.79 & 14.11 & 0.17 & 20.41 & 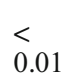 & 2.99 & $\begin{array}{l}<.01 \\
0.01\end{array}$ & 9.81 & $\begin{array}{l}0.01 \\
0.67\end{array}$ & 12.48 & 0.67 \\
\hline Medicare & 4.36 & 1.76 & $\begin{array}{l}< \\
0.01\end{array}$ & 1.18 & $<$. & 2.39 & 0.42 & 2.62 & 0.12 & 1.12 & $\begin{array}{l}< \\
0.01\end{array}$ & 0.73 & $\stackrel{<}{0.01}$ \\
\hline \multicolumn{14}{|l|}{ Need factors } \\
\hline $\begin{array}{l}\text { Fair or poor self-reported } \\
\text { health }\end{array}$ & 13.14 & 17.86 & $\begin{array}{l}< \\
0.01\end{array}$ & 15.82 & 0.28 & 17.38 & 0.31 & 14.46 & 0.59 & 30.61 & $\begin{array}{l}< \\
0.01\end{array}$ & 15.14 & 0.69 \\
\hline $\begin{array}{l}\text { One or more chronic } \\
\text { conditions }\end{array}$ & 65.73 & 49.14 & $\begin{array}{l}< \\
0.01\end{array}$ & 43.97 & $\begin{array}{l}< \\
0.01\end{array}$ & 31.98 & $\begin{array}{l}< \\
0.01\end{array}$ & 66.13 & 0.03 & 37.76 & $\begin{array}{l}< \\
0.01\end{array}$ & 52.85 & 0.10 \\
\hline \multicolumn{14}{|l|}{ Acculturation factors } \\
\hline Born in the USA & 89.78 & 32.16 & $<$ & 30.01 & $\begin{array}{l}< \\
0.01\end{array}$ & 24.18 & $<$. & 36.49 & $\begin{array}{l}<.01 \\
0.01\end{array}$ & 20.81 & $<$. & 70.02 & $\begin{array}{l}< \\
0.01\end{array}$ \\
\hline US citizen & 96.55 & 77.73 & $\begin{array}{l}< \\
0.01\end{array}$ & 75.01 & $\begin{array}{l}< \\
0.01\end{array}$ & 60.17 & $\begin{array}{l}< \\
0.01\end{array}$ & 81.66 & $\begin{array}{l}< \\
0.01\end{array}$ & 87.81 & $\begin{array}{l}< \\
0.01\end{array}$ & 82.72 & $\begin{array}{l}< \\
0.01\end{array}$ \\
\hline \multicolumn{14}{|l|}{ Percent of life in the USA } \\
\hline $0-20$ & 1.68 & 14.17 & $<$ & 18.92 & $<$ & 14.78 & $<$ & 11.29 & $<$ & 12.57 & $<$ & 5.03 & $<$ \\
\hline $21-40$ & 1.89 & 14.89 & 0.01 & 17.08 & 0.01 & 16.78 & 0.01 & 13.17 & 0.01 & 15.20 & 0.01 & 5.98 & 0.01 \\
\hline $41-60$ & 2.25 & 17.78 & & 16.31 & & 16.89 & & 17.52 & & 25.08 & & 9.68 & \\
\hline $61-80$ & 1.95 & 12.18 & & 12.21 & & 13.21 & & 8.56 & & 21.16 & & 5.34 & \\
\hline 81 or more & 92.22 & 41.01 & & 35.48 & & 38.33 & & 49.46 & & 25.99 & & 73.96 & \\
\hline English proficiency & 99.68 & 82.22 & $\begin{array}{l}< \\
0.01\end{array}$ & 78.89 & $\begin{array}{l}<.01 \\
0.01\end{array}$ & 74.13 & $\begin{array}{l}< \\
0.01\end{array}$ & 97.26 & $\begin{array}{l}< \\
0.01\end{array}$ & 60.51 & $\begin{array}{l}< \\
0.01\end{array}$ & 94.81 & $\begin{array}{l}<.01 \\
0.01\end{array}$ \\
\hline
\end{tabular}

${ }^{*} p$ value according to $\chi^{2}$ tests for differences, relative to non-Hispanic White respondents. Survey weights were applied to reflect population distributions 
third of Vietnamese respondents reported income of $0-138 \%$ of the federal poverty level, more than double the proportion of White respondents $(14.34 \%, p<0.01)$. Significantly more Vietnamese respondents $(29.47 \%)$ reported Medicaid coverage relative to their White peers $(14.61 \%, p<0.01)$, while more Korean $(20.41 \%)$ respondents reported individually purchased insurance relative to Whites $(10.92 \%, p<0.01)$. In Appendix Table 6, we report characteristics of respondents who reported "Other Asian" ethnicity or who reported more than one Asian ethnicity (e.g., Chinese and Vietnamese).

Table 2 summarizes the association between race or ethnic subgroup and being uninsured. Both in the aggregate and disaggregated, there were no statistically significant differences in uninsurance between Asian Americans and White respondents.

As shown in Table 3, significantly fewer Asian Americans had a usual source of care relative to their White peers in the aggregate $(80.02 \%$ vs. $88.06 \%, p<0.01)$, as were Korean $(63.85 \%, p<0.01)$ and Vietnamese $(77.97 \%, p<0.01)$ respondents when disaggregated. In the aggregate, this disparity persisted across our models that adjusted for predisposing, enabling, and need factors, but was no longer significant when acculturation factors were included (model 5, AOR $=0.76, p=$ 0.11 ). Vietnamese respondents were no longer significantly less likely to have a usual source of care after adjusting for predisposing (model 2, AOR $=0.47, p=0.02$ ); however, Koreans were significantly less likely to have a usual source of care across all adjusted models (model 5, AOR $=0.31, p<0.01$ ).

In Table 4, significantly fewer Asian Americans (aggregate) reported delaying necessary medical care compared with White respondents $(9.31 \%$ vs. $18.32 \%, p<0.01)$ in unadjusted analyses - in particular, Chinese $(7.88 \%, p<0.01)$, Filipino $(8.83 \%, p<0.01)$, and Vietnamese $(6.72 \%, p<0.01)$. In terms of magnitude and significance, these associations in both the aggregate and for Chinese and Vietnamese respondents persisted as models included predisposing, enabling, need, and acculturation factors. The association was no longer significant for Filipino respondents upon inclusion of acculturation factors $(\mathrm{AOR}=0.43, p=0.01)$. Similarly, Asian
Americans (aggregate) were significantly less likely to report delaying or not getting prescription medications relative to White respondents $(6.31 \%$ vs. $12.71 \%, p<0.01)$ in unadjusted analyses, as presented in Table 5. In disaggregated, unadjusted analyses, Chinese $(3.91 \%, p<0.01)$ respondents were significantly less likely to report delaying or not getting prescription medications. Estimates were comparable in magnitude and significance when incrementally adjusting for predisposing, enabling, need, and acculturation factors.

Among those who reported a usual source of care, Asian Americans (aggregate) were significantly more likely to be going to a clinic or health center relative to White respondents (32.03\% vs. $21.23 \%, p<0.01)$. Chinese $(38.20 \%, p<0.01)$ and Filipino $(37.01 \%, p<0.01)$ respondents were more likely to report a clinic or health center as their usual source of care (Appendix Table 7) compared with White respondents. In terms of magnitude and significance, these associations remained across our five models.

Sensitivity analyses that included those who identified as "Other Asian" or who reported multiple subgroups did not alter our aggregated results in terms of significance or magnitude for our outcomes.

\section{DISCUSSION}

We identified significant differences in access to care between White and Asian American non-elderly adults in California, a finding that persisted (1) in unadjusted and adjusted analyses and (2) in an aggregate Asian American group and when disaggregated by subgroup. Direction and magnitude of associations, however, varied, reflecting heterogeneity in the experiences of access to care across subgroups. Previous studies suggest significant associations between access to care and measures of acculturation, such as limited English proficiency, citizenship, and time spent in the USA and access to care. ${ }^{28,31,32}$ Our study builds upon this work by using contemporary data after ACA coverage expansions for five Asian subgroups. For some of our

Table 2 Association Between Race and Uninsurance Among Non-Hispanic White and Asian Adults Age 18-64 in California, 2014-2016

\begin{tabular}{|c|c|c|c|c|c|c|c|c|c|c|c|c|}
\hline \multirow[t]{2}{*}{ Race/ethnic subgroup } & \multicolumn{2}{|c|}{$\begin{array}{l}\text { Unadjusted } \\
\text { rates }\end{array}$} & \multicolumn{2}{|c|}{$\begin{array}{l}\text { Model 1: } \\
\text { unadjusted }\end{array}$} & \multicolumn{2}{|c|}{$\begin{array}{l}\text { Model 2*: } \\
\text { predisposing }\end{array}$} & \multicolumn{2}{|c|}{$\begin{array}{l}\text { Model } 3^{\dagger} \text { : } \\
\text { predisposing, } \\
\text { enabling }\end{array}$} & \multicolumn{2}{|c|}{$\begin{array}{l}\text { Model } 4 * \\
\text { predisposing, } \\
\text { enabling, } \\
\text { need }\end{array}$} & \multicolumn{2}{|c|}{$\begin{array}{l}\text { Model } 5^{\S} \text { : } \\
\text { predisposing, } \\
\text { enabling, } \\
\text { need, } \\
\text { acculturation }\end{array}$} \\
\hline & $\%$ & $p$ & OR & $p$ & AOR & $p$ & AOR & $p$ & AOR & $p$ & AOR & $p$ \\
\hline Non-Hispanic White (ref) & 7.28 & - & 1.00 & - & 1.00 & - & 1.00 & - & 1.00 & - & 1.00 & - \\
\hline Asian Americans (aggregate) & 10.26 & 0.01 & 1.46 & 0.01 & 1.62 & $<0.01$ & 1.45 & 0.03 & 1.48 & 0.02 & 1.12 & 0.58 \\
\hline Chinese & 9.03 & 0.32 & 1.26 & 0.33 & 1.41 & 0.17 & 1.28 & 0.32 & 1.28 & 0.31 & 0.86 & 0.63 \\
\hline Korean & 10.48 & 0.20 & 1.49 & 0.21 & 1.75 & 0.11 & 1.49 & 0.26 & 1.47 & 0.28 & 0.93 & 0.84 \\
\hline Filipino & 10.62 & 0.12 & 1.51 & 0.12 & 1.62 & 0.09 & 1.48 & 0.17 & 1.51 & 0.15 & 1.25 & 0.46 \\
\hline Vietnamese & 12.68 & 0.02 & 1.85 & 0.02 & 2.01 & 0.02 & 1.69 & 0.06 & 1.79 & 0.04 & 1.37 & 0.35 \\
\hline Japanese & 8.45 & 0.75 & 1.18 & 0.74 & 1.50 & 0.40 & 1.55 & 0.36 & 1.62 & 0.31 & 1.45 & 0.45 \\
\hline
\end{tabular}

*Predisposing factors were age, gender, highest level of education attained, marital status, and household size

${ }^{\prime}$ Enabling factors were household income measured as a percentage of the federal poverty level, employment status, and urban/rural designation

${ }^{*}$ Need factor was self-reported health status

${ }^{\S}$ Acculturation factors were being born in the USA, being a US citizen, percent of life spent in the USA, and English proficiency 
Table 3 Association Between Race and Reporting a Usual Source of Care Among Non-Hispanic White and Asian Adults Age 18-64 in California, 2014-2016

\begin{tabular}{|c|c|c|c|c|c|c|c|c|c|c|c|c|}
\hline \multirow[t]{2}{*}{ Race/ethnic subgroup } & \multicolumn{2}{|c|}{$\begin{array}{l}\text { Unadjusted } \\
\text { rates }\end{array}$} & \multicolumn{2}{|c|}{$\begin{array}{l}\text { Model 1: } \\
\text { unadjusted }\end{array}$} & \multicolumn{2}{|c|}{$\begin{array}{l}\text { Model 2*: } \\
\text { predisposing }\end{array}$} & \multicolumn{2}{|c|}{$\begin{array}{l}\text { Model } 3^{\dagger}: \\
\text { predisposing, } \\
\text { enabling }\end{array}$} & \multirow{2}{*}{$\begin{array}{l}\text { Model } 4: \\
\text { predisposing, } \\
\text { enabling, need } \\
\text { AOR }\end{array}$} & \multicolumn{3}{|c|}{$\begin{array}{l}\text { Model } 5^{\S} \text { : predisposing, } \\
\text { enabling, need, } \\
\text { acculturation }\end{array}$} \\
\hline & $\%$ & $p$ & OR & $p$ & AOR & $p$ & AOR & $p$ & & $p$ & AOR & $p$ \\
\hline Non-Hispanic White (ref) & 88.06 & - & 1.00 & - & 1.00 & - & 1.00 & - & 1.00 & - & 1.00 & - \\
\hline $\begin{array}{l}\text { Asian Americans } \\
\text { (aggregate) }\end{array}$ & 80.02 & $\begin{array}{l}< \\
0.01\end{array}$ & 0.54 & $\begin{array}{l}< \\
0.01\end{array}$ & 0.55 & $\begin{array}{l}< \\
0.01\end{array}$ & 0.61 & $\begin{array}{l}< \\
0.01\end{array}$ & 0.60 & $\begin{array}{l}< \\
0.01\end{array}$ & 0.76 & 0.11 \\
\hline Chinese & 81.84 & 0.01 & 0.61 & 0.02 & 0.66 & 0.05 & 0.72 & 0.14 & 0.70 & 0.12 & 0.91 & 0.73 \\
\hline Korean & 63.85 & $\begin{array}{l}< \\
0.01\end{array}$ & 0.24 & $\begin{array}{l}< \\
0.01\end{array}$ & 0.22 & $\begin{array}{l}< \\
0.01\end{array}$ & 0.23 & $\begin{array}{l}< \\
0.01\end{array}$ & 0.23 & $\begin{array}{l}< \\
0.01\end{array}$ & 0.31 & $\begin{array}{l}< \\
0.01\end{array}$ \\
\hline Filipino & 85.24 & 0.24 & 0.78 & 0.24 & 0.79 & 0.28 & 0.89 & 0.57 & 0.88 & 0.53 & 1.07 & 0.77 \\
\hline Vietnamese & 77.97 & $\begin{array}{l}< \\
0.01\end{array}$ & 0.48 & $\begin{array}{l}< \\
0.01\end{array}$ & 0.47 & 0.02 & 0.58 & 0.09 & 0.54 & 0.06 & 0.65 & 0.22 \\
\hline Japanese & 80.87 & 0.12 & 0.57 & 0.12 & 0.47 & 0.05 & 0.48 & 0.04 & 0.46 & 0.04 & 0.50 & 0.06 \\
\hline
\end{tabular}

* Predisposing factors were age, gender, highest level of education attained, marital status, and household size

${ }^{\dagger}$ Enabling factors were household income measured as a percentage of the federal poverty level, employment status, urban/rural designation, and being uninsured

${ }^{7}$ Need factor was self-reported health status

${ }^{\S}$ Acculturation factors were being born in the USA, being a US citizen, percent of life spent in the USA, and English proficiency

outcomes, disparities between Whites and Asian Americans - both aggregated and disaggregated - attenuated upon inclusion of acculturation factors. These findings, supported by previous studies, suggest that acculturation mediates the relationship between ethnicity and access to care. ${ }^{18,20,33}$ The impact of acculturation may vary by Asian subgroup, further supporting the importance of disaggregated analyses.

\section{Uninsured}

Before the ACA, Asian Americans reported higher uninsurance rates relative to White adults, a gap attributed in part to higher rates of employment in small businesses that did not offer health insurance benefits. ${ }^{34}$ Studies predating the ACA identified variation in the sociodemographic and acculturationrelated characteristics associated with uninsurance across Asian American subgroups in California. ${ }^{17}$ Following the ACA, disparities in insurance coverage between White and Asian American respondents appear to have attenuated, perhaps reflecting targeted outreach - which relied on a network of hundreds of community organizations, churches, and small businesses - and availability of in-language assistance for enrollment in California's marketplace, Covered California. ${ }^{15,}$, 35, ${ }^{36}$ In the first few months of the ACA implementation, more than $20 \%$ of new Covered California enrollees were of Asian descent. An estimated 57\% of Chinese, $65 \%$ of Vietnamese, and $70 \%$ of Korean new enrollees in Covered California plans did so through insurance agents. ${ }^{37}$

Our results also suggest that, following the ACA, there was heterogeneity in the distribution of insurance types across Asian American subgroups, a finding consistent with a study using 2003 and 2005 CHIS data. ${ }^{17}$ In comparison with previous estimates using CHIS, we found that there were decreases in the proportion of Asian Americans (aggregated and disaggregated) who were uninsured, and there were increases in having individually purchased and public insurance in some subgroups following ACA implementation.

\section{Usual Source of Care}

In studies predating the ACA, Asian Americans in California were significantly less likely to have a usual source of care

Table 4 Association Between Race and Delaying Medical Care in the Past 12 Months Among Non-Hispanic White and Asian Adults Age 18-64 in California, 2014-2016

\begin{tabular}{|c|c|c|c|c|c|c|c|c|c|c|c|c|}
\hline \multirow[t]{2}{*}{ Race/ethnic subgroup } & \multicolumn{2}{|c|}{$\begin{array}{l}\text { Unadjusted } \\
\text { rates }\end{array}$} & \multicolumn{2}{|c|}{$\begin{array}{l}\text { Model 1: } \\
\text { unadjusted }\end{array}$} & \multicolumn{2}{|c|}{$\begin{array}{l}\text { Model 2*: } \\
\text { predisposing }\end{array}$} & \multicolumn{2}{|c|}{$\begin{array}{l}\text { Model } 3^{\dagger} \text { : } \\
\text { predisposing, } \\
\text { enabling }\end{array}$} & \multicolumn{2}{|c|}{$\begin{array}{l}\text { Model } 4: \\
\text { predisposing, } \\
\text { enabling, need }\end{array}$} & \multicolumn{2}{|c|}{$\begin{array}{l}\text { Model } 5^{\S} \text { : } \\
\text { predisposing, } \\
\text { enabling, need, } \\
\text { acculturation }\end{array}$} \\
\hline & $\%$ & $p$ & OR & $p$ & AOR & $p$ & AOR & $p$ & AOR & $p$ & AOR & $p$ \\
\hline Non-Hispanic White (ref) & 18.32 & - & 1.00 & - & 1.00 & - & 1.00 & - & 1.00 & - & 1.00 & - \\
\hline Asian Americans (aggregate) & 9.31 & $<0.01$ & 0.46 & $<0.01$ & 0.46 & $<0.01$ & 0.44 & $<0.01$ & 0.40 & $<0.01$ & 0.48 & $<0.01$ \\
\hline Chinese & 7.88 & $<0.01$ & 0.38 & $<0.01$ & 0.38 & $<0.01$ & 0.36 & $<0.01$ & 0.33 & $<0.01$ & 0.42 & $<0.01$ \\
\hline Korean & 17.39 & 0.86 & 0.94 & 0.86 & 0.97 & 0.93 & 0.91 & 0.79 & 0.86 & 0.68 & 1.05 & 0.90 \\
\hline Filipino & 8.83 & $<0.01$ & 0.43 & $<0.01$ & 0.43 & $<0.01$ & 0.41 & $<0.01$ & 0.38 & $<0.01$ & 0.43 & 0.01 \\
\hline Vietnamese & 6.72 & $<0.01$ & 0.32 & $<0.01$ & 0.32 & $<0.01$ & 0.30 & $<0.01$ & 0.25 & $<0.01$ & 0.34 & $<0.01$ \\
\hline Japanese & 9.92 & 0.09 & 0.49 & 0.11 & 0.47 & 0.10 & 0.47 & 0.10 & 0.44 & 0.07 & 0.44 & 0.08 \\
\hline
\end{tabular}

*Predisposing factors were age, gender, highest level of education attained, marital status, and household size

${ }^{\dagger}$ Enabling factors were household income measured as a percentage of the federal poverty level, employment status, urban/rural designation, and being uninsured

${ }^{*}$ Need factor was self-reported health status

${ }^{\S}$ Acculturation factors were being born in the USA, being a US citizen, percent of life spent in the USA, and English proficiency 
Table 5 Association Between Race and Delaying or Not Filling Prescription Medication in the Past 12 Months Among Non-Hispanic White and Asian Adults Age 18-64 in California, 2014-2016

\begin{tabular}{|c|c|c|c|c|c|c|c|c|c|c|c|c|}
\hline \multirow[t]{2}{*}{ Race/ethnic subgroup } & \multicolumn{2}{|c|}{$\begin{array}{l}\text { Unadjusted } \\
\text { rates }\end{array}$} & \multicolumn{2}{|c|}{$\begin{array}{l}\text { Model 1: } \\
\text { unadjusted }\end{array}$} & \multicolumn{2}{|c|}{$\begin{array}{l}\text { Model 2*: } \\
\text { predisposing }\end{array}$} & \multicolumn{2}{|c|}{$\begin{array}{l}\text { Model } 3^{\dagger} \text { : } \\
\text { predisposing, } \\
\text { enabling }\end{array}$} & \multicolumn{2}{|c|}{$\begin{array}{l}\text { Model } 4: \\
\text { predisposing, } \\
\text { enabling, need }\end{array}$} & \multicolumn{2}{|c|}{$\begin{array}{l}\text { Model } 5^{\S} \text { : } \\
\text { predisposing, } \\
\text { enabling, need, } \\
\text { acculturation }\end{array}$} \\
\hline & $\%$ & $p$ & OR & $p$ & AOR & $p$ & AOR & $p$ & AOR & $p$ & AOR & $p$ \\
\hline Non-Hispanic White (ref) & 12.71 & - & 1.00 & - & 1.00 & - & 1.00 & - & 1.00 & - & 1.00 & - \\
\hline Asian Americans (aggregate) & 6.31 & $<0.01$ & 0.46 & $<0.01$ & 0.48 & $<0.01$ & 0.47 & $<0.01$ & 0.41 & $<0.01$ & 0.52 & $<0.01$ \\
\hline Chinese & 3.91 & $<0.01$ & 0.28 & $<0.01$ & 0.30 & $<0.01$ & 0.29 & $<0.01$ & 0.25 & $<0.01$ & 0.30 & $<0.01$ \\
\hline Korean & 2.94 & $<0.01$ & 0.21 & 0.02 & 0.22 & 0.03 & 0.21 & 0.03 & 0.19 & 0.02 & 0.23 & 0.03 \\
\hline Filipino & 10.16 & 0.36 & 0.78 & 0.36 & 0.82 & 0.47 & 0.80 & 0.42 & 0.72 & 0.25 & 0.86 & 0.63 \\
\hline Vietnamese & 6.16 & 0.05 & 0.45 & 0.06 & 0.44 & 0.06 & 0.41 & 0.05 & 0.33 & 0.02 & 0.39 & 0.09 \\
\hline Japanese & 6.64 & 0.09 & 0.49 & 0.10 & 0.49 & 0.10 & 0.49 & 0.11 & 0.44 & 0.08 & 0.48 & 0.12 \\
\hline
\end{tabular}

*Predisposing factors were age, gender, highest level of education attained, marital status, and household size

${ }^{\dagger}$ Enabling factors were household income measured as a percentage of the federal poverty level, employment status, urban/rural designation, and being uninsured

${ }^{*}$ Need factor was self-reported health status

${ }^{\S}$ Acculturation factors were being born in the USA, being a US citizen, percent of life spent in the USA, and English proficiency

relative to Whites. ${ }^{19,}{ }^{20}$ In the aggregate, our findings are consistent; however, we build upon these findings by disaggregating into five Asian American subgroups, wherein Korean respondents were significantly less likely to report having a usual source of care. A study using 2005 and 2009 CHIS data indicated Koreans were significantly less likely to report having a usual source of care relative to other Asian American subgroups, and this was attributed to higher rates of uninsurance. Our study suggests that, following the ACA, Koreans had similar rates of uninsurance relative to Whites, yet were still significantly less likely to report having a usual source of care. This finding persisted even after adjusting for predisposing, enabling, need, and acculturation factors. Vietnamese respondents were significantly less likely to report a usual source of care relative to White respondents; however, for Vietnamese respondents, the association was no longer significant after adjusting for predisposing factors.

Among those with a usual source of care, Asian Americans-specifically Chinese and Filipino respondents - were significantly more likely to go to a clinic or health center relative to Whites, which was consistent with previous studies. ${ }^{38}$ Differences in site of usual source of care among Asian Americans have previously been explained in part by attitudes and perceptions about discrimination in health care. ${ }^{38}$ That the site of care for some Asian American subgroups was a health center or clinic could reflect need for or availability of enabling services (e.g., on-site language interpretation services, transportation services, and culturally proficient care). ${ }^{11,39}$

\section{Delays in Necessary Medical Care and Prescription Drugs}

Our finding that Asian Americans in the aggregate were significantly less likely to report delays in necessary medical care or prescription drugs is consistent with a recent analysis, which suggested that, following ACA implementation, Asian Americans were significantly less likely to report delaying necessary care specifically because of cost. ${ }^{10}$ Our disaggregated findings - wherein Chinese and Vietnamese respondents were significantly less likely to report delays in necessary medical care - align with a study preceding the ACA, and the authors suggested these findings reflect different cultural preferences and a more crisis-oriented perspective on access to care among Asian Americans. ${ }^{19}$ Our study builds upon this analysis by estimating the odds of delaying necessary care or prescription medication following the ACA, and by examining these outcomes for Japanese and Korean adults, who reported statistically comparable rates relative to their White peers.

\section{State Policies in Disaggregation of Asian American Data}

During the Obama administration, the White House Initiative on Asian Americans began to identify methods of collecting and reporting more detailed subgroup data in federal surveys. ${ }^{40}$ There has been more movement at the state level: a bill requiring disaggregated data collection passed the California State Assembly and was signed into law in 2016. ${ }^{41,42}$ Similar legislation passed in New York and Massachusetts the following year. Some civil rights groups and lawmakers argue that the disaggregated information may provide further information on disparities in poverty, education, and health care that currently go unnoticed in a diverse group and can inform community needs. ${ }^{43,}{ }^{44}$ Opponents of the legislation suggest that the policy unfairly targets only Asian Americans, and that there are potential unintended consequences in disaggregation, particularly in terms of education. ${ }^{45}$

\section{Limitations}

Our study did not estimate the causal impact of the Affordable Care Act on access to care for Asian Americans. The data in our study are limited to adults in California, and therefore our results may not be representative of outcomes in other states or nationwide. Notably, about $16 \%$ of the Californian population is Asian American, which is higher than the national average $(6 \%) .{ }^{46}$ Moreover, some counties in California expanded Medicaid eligibility before 2014, which we are unable to 
account for in the data; nevertheless, the CHIS is one of the few publicly available data sources that has collected more granular Asian subgroup data for multiple years, and an estimated $31 \%$ of non-elderly Asian Americans in the USA reside in California. ${ }^{1,47}$ Further, our sampling strategy excluded individuals who self-identified as Asian American but either identified as "Other Asian" or reported multiple subgroups, which prevented us from assessing further intra-racial heterogeneity. Examining access to care for multiracial populations is important for future studies. We ran sensitivity analyses to include respondents who reported multiple Asian ethnicities or identified as "Other Asian," in our aggregate analyses, which did not change the significance or direction for most of our findings. Lastly, our models currently compare differences between non-Hispanic White and Asian American nonelderly adults, and it is possible that non-Hispanic White adults would not be the appropriate comparator group. ${ }^{48}$

Our findings identified critical differences in access to care between White and Asian American adults in California following the ACA, but these differences varied substantially among Asian American subgroups. These results suggest a potential benefit to collecting disaggregating data - particularly as it pertains to health care data — for Asian Americans, and can potentially inform more targeted public policy and program interventions to mitigate gaps in access to care.

Corresponding Author: Kevin H. Nguyen, MS; Brown University School of Public Health, Providence, RI, USA (e-mail: kevin nguyen2@brown.edu).

Funding Information Kevin H. Nguyen completed this work while supported by an Agency for Healthcare Research and Buality National Research Service Award Grant (Grant No. T32 HSOOOO1132) and the Robert Wood Johnson Foundation Health Policy Research Scholars program.

\section{Compliance with Ethical Standards:}

Conflict of Interest: The authors declare that they do not have a conflict of interest.

Institutional Review Board Approval: IRB approval was not needed, as this project used publicly available, de-identified California Health Interview Survey data from the University of California, Los Angeles.

Disclaimer: The views expressed in this article are those of the authors and do not necessarily reflect the position or policy of the Department of Veterans Affairs or the US government.

\section{REFERENCES}

1. Kaiser Family Foundation. Health and Health Care for Asian Americans, Native Hawaiians and other Pacific Islanders (NHOPIs) in the United States. https://www.kff.org/infographic/health-and-health-care-forasian-americans-native-hawaiians-and-other-pacific-islanders-nhopisin-the-united-states/. Accessed 13 May 2019.
2. Chin KK. Improving Public Health Surveillance About Asian Americans, Native Hawaiians, and Pacific Islanders. Am J Public Health 2017;107(6):827-8. https://doi.org/10.2105/ajph.2017.303802

3. Ponce NA, Scheitler A, Shimkhada R. Understanding the Culture of Health for Asian American, Native Hawaiian and Pacific Islanders (AANHPIs): What do population-based health surveys across the nation tell us about the state of data disaggregation for AANHPIs? 2017.

4. Srinivasan S, Guillermo T. Toward improved health: disaggregating Asian American and Native Hawaiian/Pacific Islander data. Am J Public Health 2000;90(11):1731-4.

5. Holland AT, Palaniappan LP. Problems With the Collection and Interpretation of Asian-American Health Data: Omission, Aggregation, and Extrapolation. Ann Epidemiol 2012;22(6):397-405. https://doi.org/10. 1016/j.annepidem.2012.04.001

6. Park H, Choi E, Park Y-S, Wenzel JA. Racial and Ethnic Differences in Mental Health among Asian Americans and Non-Hispanic Whites: Based on California Health Interview Survey. Issues Ment Health Nurs 2018;39(3):208-14

7. Nguyen TH, Nguyen T-N, Taylor Fischer WH, Tran TV. Type 2 diabetes among Asian Americans: Prevalence and prevention. World J Diabetes 2015;6(4):543.

8. Mui P, Bowie JV, Juon H-S, Thorpe Jr RJ. Ethnic group differences in health outcomes among Asian American men in California. Am J Mens Health 2017;11(5):1406-14.

9. Paek M-S, Lim J-W. Factors associated with health care access and outcome. Soc Work Health Care 2012;51(6):506-30.

10. Artiga S, Foutz J, Cornachione E. Key facts on health and health care by race and ethnicity. 2016. Henry J Kaiser Family Foundation: Washingon DC 2017.

11. Weir RC, Emerson HP, Tseng W, Chin MH, Caballero J, Song H, et al. Use of enabling services by Asian American, Native Hawaiian, and Other Pacific Islander Patients at 4 community health centers. Am J Public Health 2010;100(11):2199-205.

12. Ngo-Metzger 8, Massagli MP, Clarridge BR, Manocchia M, Davis RB, Iezzoni LI, et al. Linguistic and cultural barriers to care. J Gen Intern Med 2003;18(1):44-52.

13. Islam NS, Khan S, Kwon S, Jang $\mathbf{D}$, Ro M, Trinh-Shevrin C. Methodological issues in the collection, analysis, and reporting of granular data in Asian American populations: historical challenges and potential solutions. J Health Care Poor Underserved 2010;21(4): 1354.

14. Tendulkar SA, Hamilton RC, Chu C, Arsenault L, Duffy $\mathbf{K}$, Huynh V, et al. Investigating the myth of the "model minority": a participatory community health assessment of Chinese and Vietnamese adults. J Immigr Minor Health 2012;14(5):850-7.

15. Park JJ, Humble S, Sommers BD, Colditz GA, Epstein AM, Koh HK. Health insurance for asian americans, native hawaiians, and pacific islanders under the affordable care act. JAMA Intern Med 2018. https:// doi.org/10.1001/jamainternmed.2018.1476

16. Islam N, S.Yi S, Trinh-Shevrin C. The Impact of the Affordable Care Act on Health Insurance Coverage for Asian Americans. Am J Public Health 2017;107(1):e12-e3. https://doi.org/10.2105/ajph.2016.303530

17. Kao D. Factors associated with ethnic differences in health insurance coverage and type among Asian Americans. J Community Health 2010;35(2): 142-55.

18. Chang $\mathbf{E}$, Chan KS. Understanding Pathways to Usual Source of Care among Asian Americans. J Health Care Poor Underserved 2016;27(2):793-814.

19. Chang E, Chan KS. Variations in Asian Americans: how neighborhood concordance is associated with health care access and utilization. Am J Public Health 2015; 105(1):66-8.

20. Chang E, Chan KS, Han H-R. Effect of acculturation on variations in having a usual source of care among Asian Americans and non-Hispanic whites in California. Am J Public Health 2015;105(2):398-407.

21. California Health Interview Survey. What is CHIS? http://healthpolicy. ucla.edu/chis/about/Pages/what-is-chis.aspx. Accessed 13 May 2019.

22. Aday LA. Andersen R. A framework for the study of access to medical care. Health Serv Res 1974;9(3):208.

23. Andersen R, Harada N, Chiu V, Makinodan T. Application of the behavioral model to health studies of Asian and Pacific Islander Americans. Asian Am Pac Isl J Health 1995;3(2):128-41.

24. Pitkin Derose K, Bahney BW, Lurie N, Escarce JJ. Immigrants and health care access, quality, and cost. Med Care Res Rev 2009;66(4):355408.

25. Chang E. Factors associated with having a usual source of care in an ethnically diverse sample of Asian American adults. Med Care. 
$2014 ; 52(9): 833$ - EOA. https://doi.org/10.1097/MLR. 0000000000000187

26. Wang J, Trivedi AN. Enrollment in California's Medicaid Program After the Affordable Care Act Expansion. Am J Public Health 2017;107(11):1757-9.

27. Andersen RM, Davidson PL, Baumeister SE. Improving access to care. Changing the US health care system: key issues in health services policy and management. San Francisco: Jossey-Bass. 2014:33-69.

28. Ponce NA, Hays RD, Cunningham WE. Linguistic disparities in health care access and health status among older adults. J Gen Intern Med 2006;21(7):786-91.

29. Kuo J, Porter K. Health status of Asian Americans: United States, 199294: US Department of Health and Human Services, Centers for Disease Control and Prevention; 1998.

30. Rao AK, Daniels K, E1-Sayed YY, Moshesh MK, Caughey AB. Perinatal outcomes among Asian American and Pacific islander women. Am J Obstet Gynecol 2006; 195(3):834-8.

31. Ye J, Mack D, Fry-Johnson Y, Parker K. Health Care Access and Utilization Among US-Born and Foreign-Born Asian Americans. J Immigr Minor Health / Center for Minority Public Health 2012;14(5):731-7. https://doi.org/10.1007/s10903-011-9543-9

32. Parker Frisbie $\mathbf{W}$, Cho $\mathbf{Y}$, Hummer RA. Immigration and the health of Asian and Pacific Islander adults in the United States. Am J Epidemiol 2001;153(4):372-80.

33. Clough J, Lee S, Chae DH. Barriers to health care among Asian immigrants in the United States: a traditional review. J Health Care Poor Underserved 2013;24(1):384-403.

34. Cook WK, Tseng W, Chin KK, John I, Chung C. Identifying vulnerable Asian Americans under health care reform: working in small businesses and health care coverage. $J$ Health Care Poor Underserved 2014;25(4):1898-921.

35. Cook WK, John I, Chung C, Tseng W, Lee JP. Medicaid Expansion and Healthcare Access: Lessons from Asian American and Pacific Islander Experiences in California. J Immigr Minor Health 2017;19(4):995-9.

36. Shinkman R. Getting Underserved Groups to Seek Health Insurance. NEJM Catalyst 2016 May 16.

37. Aliferis L. In California, Asian Americans flock to health coverage NPR March 26, 2014.

38. Gaskin DJ, Arbelaez JJ, Brown JR, Petras H, Wagner FA, Cooper LA Examining racial and ethnic disparities in site of usual source of care. J Natl Med Assoc 2007;99(1):22.

39. Ngo-Metzger Q, Sorkin DH, Phillips RS, Greenfield S, Massagli MP, Clarridge B, et al. Providing high-quality care for limited English proficient patients: the importance of language concordance and interpreter use. J Gen Intern Med 2007;22(2):324-30.

40. White House Initiative on Asian Americans and Pacific Islanders. Data Disaggregation Resources. https://sites.ed.gov/aapi/aapi-data-disaggre gation/. Accessed 13 May 2019.

41. An Act to Amend Section 8310.7 of the Government Code Relating to Data Collection Calif. AB 1726 Chapter 607; 2016.

42. Fuchs C. California Governor Signs Bill to Disaggregate Asian-American Health Data. NBC News. September 272016.

43. Gibbs BK, Nsiah-Jefferson L, McHugh MD, Trivedi AN, Prothrow-Stith D. Reducing racial and ethnic health disparities: exploring an outcome oriented agenda for research and policy. J Health Polit Policy Law 2006;31(1):185-218.

44. Trivedi AN, Gibbs B, Nsiah-Jefferson L, Ayanian JZ, Prothrow-Stith D.
Creating a state minority health policy report card. Health Aff 2005;24(2):388-96.

45. Fuchs C. California Data Disaggregation Bill Sparks Debate in AsianAmerican Community. NBC News. August 262016.

46. US Census Bureau. State and County QuickFacts: California, 2018. 2018. https://www.census.gov/quickfacts/ca. Accessed 13 May 2019.

47. Kaiser Family Foundation. The California Health Care Landscape August 2015

48. Cook BL, McGuire TG, Zaslavsky AM. Measuring racial/ethnic disparities in health care: methods and practical issues. Health Serv Res. 2012;47(3pt2): 1232-54.

\section{APPENDIX}

Table 6 Respondent Characteristics, Comparing Non-Hispanic White and Other Asian Respondents in California, 2014-2016

\begin{tabular}{|c|c|c|c|}
\hline \multirow[t]{2}{*}{ Characteristic } & \multirow[t]{2}{*}{$\begin{array}{l}\text { White } \\
n=19,021\end{array}$} & \multicolumn{2}{|c|}{$\begin{array}{l}\text { Other Asian } \\
n=868\end{array}$} \\
\hline & & $\%$ & $p^{*}$ \\
\hline \multicolumn{4}{|l|}{ Predisposing factors } \\
\hline \multicolumn{4}{|l|}{ Age } \\
\hline $18-34$ & 32.44 & 53.75 & $<$ \\
\hline $35-64$ & 67.66 & 46.25 & 0.01 \\
\hline Female & 49.21 & 48.16 & 0.71 \\
\hline \multicolumn{4}{|l|}{ Education } \\
\hline Does not have high school diploma & 3.95 & 3.46 & $<$ \\
\hline High school diploma & 19.33 & 19.44 & 0.01 \\
\hline Some college & 15.74 & 9.73 & \\
\hline Vocational school/AA or AS degree & 12.09 & 6.57 & \\
\hline College degree or higher & 48.90 & 60.80 & \\
\hline Marital status: married & 51.68 & 55.12 & 0.24 \\
\hline \multicolumn{4}{|l|}{ Enabling factors } \\
\hline \multicolumn{4}{|c|}{ Income (by federal poverty level [FPL]) } \\
\hline $0-138 \%$ FPL & 14.34 & 19.40 & 0.16 \\
\hline 139-249\% FPL & 12.27 & 12.47 & \\
\hline $250-399 \%$ FPL & 17.34 & 15.37 & \\
\hline $400 \%$ FPL or more & 56.05 & 52.75 & \\
\hline Unemployed & 25.48 & 28.40 & 0.35 \\
\hline \multicolumn{4}{|l|}{ Health insurance coverage } \\
\hline Uninsured & 7.28 & 6.67 & 0.69 \\
\hline Employer-sponsored & 62.84 & 63.55 & 0.84 \\
\hline Medicaid & 14.61 & 19.58 & 0.04 \\
\hline Individually purchased & 10.92 & 7.42 & 0.05 \\
\hline Medicare & 4.36 & 2.78 & 0.19 \\
\hline \multicolumn{4}{|l|}{ Need factors } \\
\hline Fair or poor self-reported health & 13.14 & 10.42 & 0.25 \\
\hline One or more chronic conditions & 65.73 & 57.63 & $\begin{array}{l}< \\
0,01\end{array}$ \\
\hline \multicolumn{4}{|l|}{ Acculturation factors } \\
\hline Born in the USA & 89.78 & 32.97 & $<$ \\
\hline US citizen & 96.55 & 73.59 & $\begin{array}{l}< \\
0.01\end{array}$ \\
\hline \multicolumn{4}{|l|}{ Percent of life in the USA } \\
\hline $0-20$ & 1.68 & 12.70 & \\
\hline $21-40$ & 1.89 & 18.60 & 0.01 \\
\hline $41-60$ & 2.25 & 14.26 & \\
\hline $61-80$ & 1.95 & 11.01 & \\
\hline 81 or more & 92.22 & 43.43 & \\
\hline English proficiency & 99.68 & 94.59 & $\begin{array}{l}< \\
0.01\end{array}$ \\
\hline
\end{tabular}

*p value according to $\chi^{2}$ tests for differences. Estimates were weighted to reflect population averages 
Table 7 Association Between Race and Reporting a Clinic or Community Health Center as Usual Source of Care Among Non-Hispanic White and Asian Adults Age 18-64 in California, 2014-2016

\begin{tabular}{|c|c|c|c|c|c|c|c|c|c|c|c|c|}
\hline \multirow[t]{2}{*}{ Race/ethnic subgroup } & \multicolumn{2}{|c|}{$\begin{array}{l}\text { Unadjusted } \\
\text { rates }\end{array}$} & \multicolumn{2}{|c|}{$\begin{array}{l}\text { Model 1: } \\
\text { unadjusted }\end{array}$} & \multicolumn{2}{|c|}{$\begin{array}{l}\text { Model } 2 *: \\
\text { predisposing }\end{array}$} & \multicolumn{2}{|c|}{$\begin{array}{l}\text { Model } 3^{\dagger} \text { : } \\
\text { predisposing, } \\
\text { enabling }\end{array}$} & \multicolumn{2}{|c|}{$\begin{array}{l}\text { Model } 4 * \text { : } \\
\text { predisposing, } \\
\text { enabling, need }\end{array}$} & \multicolumn{2}{|c|}{$\begin{array}{l}\text { Model } 5^{\S} \text { : } \\
\text { predisposing, } \\
\text { enabling, need, } \\
\text { acculturation }\end{array}$} \\
\hline & $\%$ & $p$ & OR & $p$ & AOR & $p$ & AOR & $p$ & AOR & $p$ & AOR & $p$ \\
\hline Non-Hispanic White (ref) & 21.23 & - & 1.00 & - & 1.00 & - & 1.00 & - & 1.00 & - & 1.00 & - \\
\hline Asian Americans (aggregate) & 32.03 & $<0.01$ & 1.75 & $<0.01$ & 1.88 & $<0.01$ & 1.92 & $<0.01$ & 1.90 & $<0.01$ & 1.69 & $<0.01$ \\
\hline Chinese & 38.20 & $<0.01$ & 2.29 & $<0.01$ & 2.58 & $<0.01$ & 2.72 & $<0.01$ & 2.69 & $<0.01$ & 2.29 & $<0.01$ \\
\hline Korean & 22.19 & 0.86 & 1.06 & 0.86 & 1.20 & 0.56 & 1.23 & 0.53 & 1.22 & 0.54 & 1.00 & 0.99 \\
\hline Filipino & 37.01 & $<0.01$ & 2.19 & $<0.01$ & 2.34 & $<0.01$ & 2.35 & $<0.01$ & 2.32 & $<0.01$ & 2.03 & $<0.01$ \\
\hline Vietnamese & 19.31 & 0.67 & 0.89 & 0.67 & 0.83 & 0.53 & 0.72 & 0.29 & 0.71 & 0.27 & 0.58 & 0.17 \\
\hline Japanese & 15.87 & 0.30 & 0.70 & 0.31 & 0.80 & 0.55 & 0.96 & 0.92 & 0.95 & 0.90 & 0.89 & 0.77 \\
\hline
\end{tabular}

*Predisposing factors were age, gender, highest level of education attained, marital status, and household size

${ }^{\dagger}$ Enabling factors were household income measured as a percentage of the federal poverty level, employment status, urban/rural designation, and being uninsured

${ }^{*}$ Need factor was self-reported health status

${ }^{\S}$ Acculturation factors were being born in the USA, being a US citizen, percent of life spent in the USA, and English proficiency

Publisher's Note Springer Nature remains neutral with regard to jurisdictional claims in published maps and institutional affiliations. 